\title{
Performance of Steel Monopole Transmission Line Supporting Structure in Various Wind Zones of India
}

\author{
Ramesh. B ${ }^{1, *}$, Balaji KVGD ${ }^{1}$, Santhosh Kumar B ${ }^{2}$, Sandeep $M^{3}$, B. S Ravindra ${ }^{4}$ \\ ${ }^{1}$ Department of Civil Engineering' GITAM, Visakhapatnam, 530045, Andhra Pradesh, India \\ ${ }^{2}$ D.E.E, W.R. Department, Vizianagaram, 532201, Andhra Pradesh, India \\ ${ }^{3}$ Principle ACS, Hyderabad, 500034, Andhra Pradesh, India \\ ${ }^{4}$ Superintending Engineer, Panchayat Raj Engineering Department, Kakinada, India
}

Received April 30, 2021; Revised June 22, 2021; Accepted July 19, 2021

\section{Cite This Paper in the following Citation Styles}

(a): [1] Ramesh. B, Balaji KVGD, Santhosh Kumar B, Sandeep M, B. S Ravindra, "Performance of Steel Monopole Transmission Line Supporting Structure in Various Wind Zones of India," Civil Engineering and Architecture, Vol. 9, No. 5, pp. 1356 - 1364, 2021. DOI: 10.13189/cea.2021.090509.

(b): Ramesh. B, Balaji KVGD, Santhosh Kumar B, Sandeep M, B. S Ravindra (2021). Performance of Steel Monopole Transmission Line Supporting Structure in Various Wind Zones of India. Civil Engineering and Architecture, 9(5), 1356 - 1364. DOI: 10.13189/cea.2021.090509.

Copyright $\bigcirc 2021$ by authors, all rights reserved. Authors agree that this article remains permanently open access under the terms of the Creative Commons Attribution License 4.0 International License

\begin{abstract}
The design of every new transmission line can address the solutions to fresh engineering problem. Therefore, the selection of the monopole structures in place of conventional lattice towers summarized the obligatory design parameters. The reliability climatic wind loads and the security longitudinal broken wire load combinations influence the internal parameter assessment of the steel pole structures. To assess them, a $60 \mathrm{~m}$ high double circuit (DC) $220 \mathrm{kV}$ line with $305 \mathrm{~m}$ basic span is selected. All the Six wind zones $(33,39,44,47,50$, and $55 \mathrm{~m} / \mathrm{s})$ of India are selected to compute the transverse wind loads on the tower. Secondly broken wire security load in the longitudinal direction is adopted for the load combination for the monopole transmission tower design. With the above data, this paper presented the variation of the internal parameters in the wind zones. It is found that even though the basic wind speed from $33 \mathrm{~m} / \mathrm{s}$ to $55 \mathrm{~m} / \mathrm{s}$ is increased to $66.66 \%$, top deflection is increased by $1.6 \%$, a bending moment is enhanced by $6.3 \%$ and shear force is increased by $12.6 \%$ only. The results show the change of wind speed has a little effect on the monopole tower. However, the variations of internal parameters in the wind zone are strongly depending on the Longitudinal loading only. The ASCE 48-19 steel monopole code is adopted to design the monopole since the Indian standard design code for monopole was not found. However, when comparing with the Indian Standard general Steel code IS 800-2007(Limit state) design guidelines, the Indian steel code contributes
\end{abstract}

$10 \%$ more weight.

Keywords Monopole, Wind Zones, IS: 802 (Part-1/Sec-1): 2015, ASCE 48-19, IS 800:2007

\section{Introduction}

Historically, Steel lattice towers have been utilized to support transmission line system around the world including India. From the last three decades, the population is increasing very rapidly, consequently, the power demand is also increasing alarmingly since the 1980s. Since the population increases in leaps and bounds, urbanization is also developed very quickly. Consequently, the required land to accommodate transmission lines becomes insufficient and in the case of the acquisition, it is more premium. Hence an alternative methodology is to change the vertical configuration of the Lattice tower structure into the monopole supporting structures. These become a viable alternative in India and East-west and North-South countries around the world. With the latest state of the art manufacturing technical know-how the steel tubular poles made from stronger materials from steel, have become a better market share in India, as well.

The steel poles can be in the limited space since it requires the smaller area compared to lattice towers. 
Furthermore, the poles can be adopted with existing corridors already occupied with other projects such as highways, roads, rail tracks including the existing High transmission lines etc., Sharing of the limited space allows monopole a more direct line design results in optimizing the line cost. Secondly, the Poles have a better visual appearance. The most recent innovations of monopole towers with Next Generation Conductors, with more vivification, is advised [1, 2]. The IS Code for $11 \mathrm{kV}$ design guidelines which were printed in 1985 year introduced the usage of steel pipe poles for lower line cost when the width of ROW is limited.

The height of the tower depends on the minimum safety and security conditions of the existing objects such as charged conductors and other objects etc.. It includes the maximum mid-span sag allowances of the maximum daily temperature conditions. Since safety is a more demanding condition hence the IEC technical guidelines established the minimum Factor of Safety for tensioning the conductor. It is $50 \%$ of the rated Ultimate Material strength. Transmission tower cost varies from $25 \%$ to $40 \%$ of the total cost [3-6]. The revised loads and material requirements are detailed in [7].

Previously the deterministic climatic loads are adopted for design, however, the probabilistic climatic loads are approved (CEI/IEC/826-1994-04, 1991) [8]. The main aim is to bypass the cascading effects of the failure of the primary members. Accordingly, the strength of the tower is the primary factor in the tower system, in comparison with the Conductors strength, since conductors have a lot of reserve strength [9]. Secondly, the research report advocated the (P- $\Delta$ ) analysis when the tip deflection exceeds $2.5 \%$ of tower height. Reliability conditions of the Transverse wind load on the tower, as well as conductors, are justice, while the failure loads are weighted as security condition loads.

Even though the basic wind speed for a certain region is identified, but the isolated local conditions have discovered the heavy loading when compared to specified wind speed [10].

For the past 70years ACSR (Aluminium conductor, steel-reinforced) conductor has been utilized since it has a lower price, and economical than copper conductors [11]. The mechanical properties of the conductors are briefly explained [12].

The design guidelines for the lattice tower geometry have been advocated by the Transmission of Manual of India. But IS 5613 (Part2/sec 1) has recommended the different configurations of pole geometry for $220 \mathrm{kV}$ power lines only. Recently loading parameters for monopole tower structures have been incorporated in the revised version of IS 802(Part 1/Sec1)2015 Code. However in all the three codes cannot advocate the design guidelines, however, the ASCE /SEI 48-19quantified the design parameters for the steel transmission pole structures even for extra-high voltage systems also [13].
The primary parameter of the monopole is the tip deflection, accordingly a simplified rational solution to find the primary and secondary deflections for tapered poles $\mathrm{s}$ for lighting masts transmission line towers were derived Balagopal et al [14]. Similarly, the shell element technique was adopted to find the tip deflection by Asharaf, et al [15].

The transverse wind loads are adopted as a static load and an analytical model was developed for longitudinal broken wire loads for the perdition of the Non-linear behaviour of the tower. Only a 7\% increase in tower stress is found with the methodology [16].

Sag and tension parameters are interdependent. Sag primarily depends on the span length and tension. The mechanical tension depends on the wire temperature of the weather conditions. The parabola and the catenary curves are generally used in the calculations for conductor sags on transmission lines. Generally, the parabola calculation is fair when the sag is $0.5 \%$ of the span length. It is reported that the parabola equation has a similar calculation as the catenary. (IS 15613 Part1/sec1 -1985).

The interpreted catenary curve calculation was derived [17]. It was during the 1940s the Practical sag correction for tapes for example is determined by Rainsford [18]. Similarly, a logical formula for cable length variation with sag -span ratio is validated with numerical examples [19]. A larger span shows a higher sag of the conductor is proportional to the square of the span hence the little increase of the span produces the large sags [19].

ACSR conductors have better thermal properties than ACCR conductors. The calculation of the sag- tension of the conductor at different temperatures for various load cases of wind and ice is replicated [20].

ACCR conductor has been used as a substitute of ACSR (Aluminum conductor steel reinforced) and ACSS (Aluminum conductor steel supported) conductor to existing structures of the same tension and clearances, with more ampacity without any risks [22].

Monopoles with limited right of way for composite conductors' suitability in sag ampacity for $275 \mathrm{KV}$ line are highlighted with the low sag high-temperature characteristics of ACCR conductors [23].

\subsection{Objective of the Present Study}

Most of the above literature is related to the Lattice towers only and very nominal literature is reviewed the monopoles. On the other hand, the increased demand for electrical power requires additional power line corridors with limited right of way of the land. This paper highlights the influence of basic wind speed on the design parameters of monopole transmission tower. It also compares the American steel pole (ASCE 48-19) design procedure with IS 800:2007 dealing with general construction in steel, as specialized steel monopole design procedure was not exclusively found in the Indian 
standards code IS 802.

\section{Methodology}

The electrical power supply design is divided into mechanical and electrical components. The mechanical component is related to the conductor support systems including towers, foundations, and other related items. The conductor supporting structure is the indispensable element of a line, but the critical problems of a line are associated with the conductors only. The support structures are strong enough for the vertical loads, but the strength of the same supports is inadequate for unexpected actions developed to the conductor's system.

The $60 \mathrm{~m}$ high monopole structure geometric properties are depicted in Table 1 and figure1, similarly the conductor properties also described in table 2 . With the data the pole was modelled in STAAD pro software to find the internal parameters. The internal parameters are found with the wind loads guidelines of the IS $802-2015$ code provisions. The action of climatic loads related to the transverse wind loads on the monopole as well as conductors is computed with the Gust Factor method.

Secondly, the security loads are related to the mechanical strengths of the conductor. These are represented in the longitudinal direction of the line. In the security loads, the major condition is the broken wire condition loads are characterized for the stability of the monopole. Both reliability and Security load combinations are applied to the monopole structure. The wind loads along the height of the supporting structure are found from the designated panel heights with relevant force coefficients represented in figure2. Similarly, the wind loads on the conductors are also found with the Gust factor method.

The design of monopole sections was carried out corresponding to the ASCE 48-19 guidelines and as per IS 800:2007 as shown in table $3 \&$ \& 4 . Secondly, the sag-tensions calculations of the conductor have calculated for ACSR (Aluminum conductor steel reinforced) conductor for temperature, wind loading cases. The geometric properties are prescribed from IS 1161-2014 [25]. The revised code provisions of wind load impact on various wind sensitive structures were explored in [26-33]. Similarly, the revised code guidelines of the transmission tower loads were compared with the general wind load provisions [34]. Identifying the Monopole can be useful for urban areas, the Hoarding design in city limits was also explained with the latest load combinations [35].

The IS 800:2007, adopts the equation 1 for checking the member capacity with Combined Axial Force and Bending Moment.

$$
\frac{N}{N_{d}}+\frac{M_{y}}{M_{d y}}+\frac{M_{z}}{M_{d z}} \leq 1
$$

Where, $M_{y} M_{z}=$ factored applied moments about the minor and major axis of the cross-sections respectively. $M_{d y} M_{d z}=$ design strength under corresponding moment acting alone; $\mathrm{N}=$ factored applied axial force, $N_{d}=$ design strength in tension.

The ASCE 48-19, adopts the equation 2 for checking the member capacity of rounded for checking the compressive stress.

$$
\frac{f_{a}}{F_{a}}+\frac{f_{b}}{F_{b}} \leq 1
$$

$f_{a}=$ Compressive stress due to axial loads, (MPa), $f_{b}=$ Compressive stress due to bending moments, $(\mathrm{MPa}), F_{a}$ = Compressive stress permitted, $(\mathrm{MPa}), F_{b}=$ Bending stress permitted MPa. Do = Outside diameter of the tubular section, $\mathrm{t}=$ Wall thickness in. $(\mathrm{mm})$; and $\mathrm{E}=$ Modulus of elasticity.

Table 1. Geometrical properties of Monopole

\begin{tabular}{|c|c|c|}
\hline & \multicolumn{2}{|c|}{ Monopole Pipe Section } \\
\hline Tower height $(\mathrm{m})$ & Base Width $(\mathrm{m})$ & Top width $(\mathrm{m})$ \\
\hline 60 & 2.16 & 0.32 \\
\hline
\end{tabular}

Table 2. Properties of ACSR conductor

\begin{tabular}{|c|c|c|}
\hline Conductor material & ACSR & \\
\hline Conductor size & $30 / 7 / 3$ & $\mathrm{~mm}$ \\
\hline Overall Diameter of conductor(d) & 21 & $\mathrm{~mm}$ \\
\hline Area of the conductor for all stands (A) & 2.6154 & $\mathrm{~cm}^{2}$ \\
\hline Weight of the conductor (W) & 0.973 & $\mathrm{Kg} / \mathrm{m}$ \\
\hline $\begin{array}{c}\text { Breaking strength of the conductor } \\
\text { (UTS) }\end{array}$ & 9130 & $\mathrm{~kg}$ \\
\hline $\begin{array}{c}\text { Coefficient of linear expansion }(\alpha) \\
\text { Modulus of elasticity } € \\
\text { Initial (EI) }\end{array}$ & 0.00001773 & $\mathrm{per}{ }^{\circ} \mathrm{C}$ \\
\hline Final (EI) & 78700000 & $\mathrm{kgf} / \mathrm{cm}^{2}$ \\
\hline & 62600000 & $\mathrm{~kg} / \mathrm{cm}^{2}$ \\
\hline
\end{tabular}



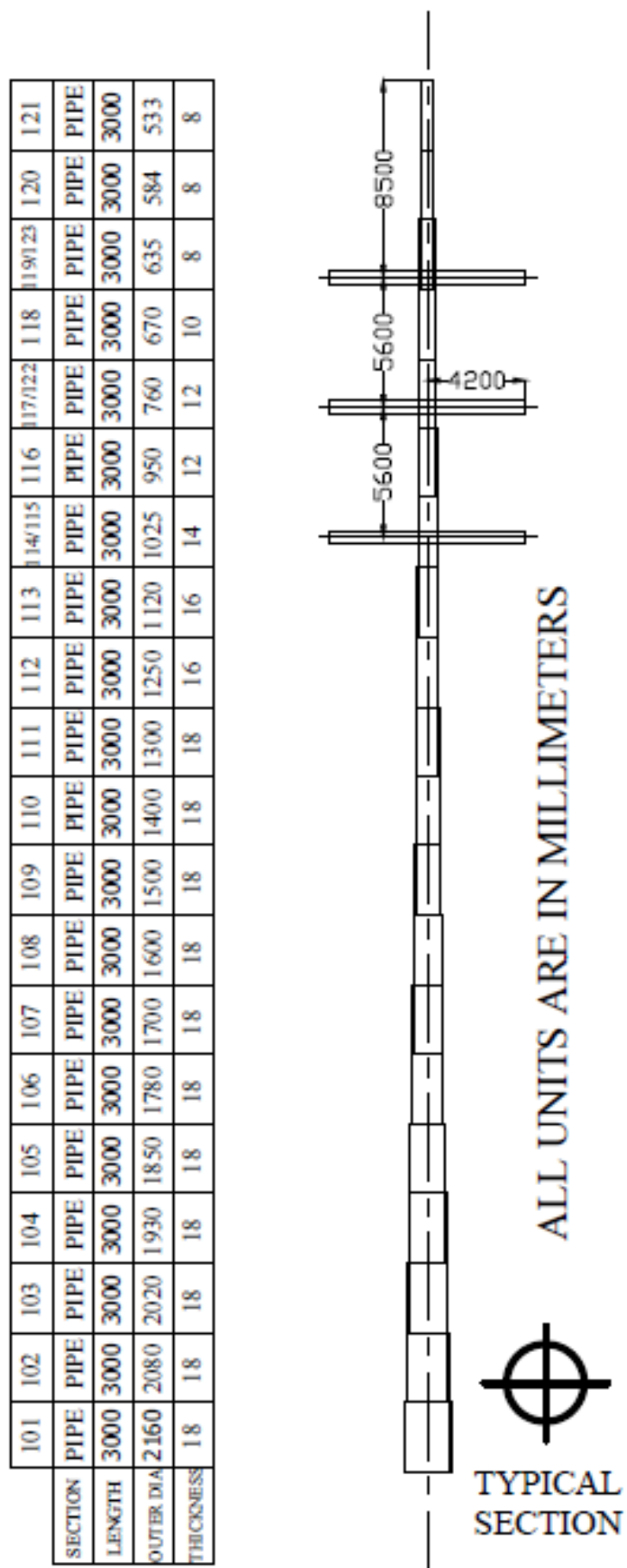

$60 \mathrm{~m}$ Transmission Tower Monopole PIPE SECTION

Figure 1. Sectional properties of Monopole 
Table 3. Monopole Design Data Conforming to ASCE 48-19

\begin{tabular}{|c|c|c|c|c|c|c|c|c|c|c|}
\hline \multirow{2}{*}{$\begin{array}{l}\text { Member } \\
\text { Numbering } \\
\text { from staad }\end{array}$} & \multicolumn{2}{|c|}{ Size } & \multirow[t]{2}{*}{$\mathrm{D} / \mathrm{t}$} & \multirow[t]{2}{*}{$\frac{f_{a}}{F_{a}}+\frac{f_{b}}{F_{b}}<=1$} & \multicolumn{2}{|c|}{ Shear Check } & \multicolumn{2}{|c|}{ Bending Check } & \multicolumn{2}{|c|}{$\begin{array}{l}\text { 5.2.6 Combined } \\
\text { Stress }\end{array}$} \\
\hline & OD & $\mathrm{t}$ & & & $\mathrm{f}_{\mathrm{v}}=0.58 \times \mathrm{f}_{\mathrm{y}}$ & $\frac{V Q}{I b}+\frac{T c}{J}<\mathrm{fv}$ & $\mathrm{Fb}$ & $\frac{M c}{I}<\mathrm{Fb}$ & $F_{y}$ or $F_{b}$ & Stress \\
\hline 101 & 2160 & 18 & 120.00 & 0.71 & 179.80 & 9.49 & 310 & 218 & 310 & 307.27 \\
\hline 102 & 2080 & 18 & 115.56 & 0.72 & 179.80 & 9.82 & 310 & 221 & 310 & 309.41 \\
\hline 103 & 2020 & 18 & 112.22 & 0.71 & 179.80 & 10.07 & 310 & 218 & 310 & 304.99 \\
\hline 104 & 1930 & 18 & 107.22 & 0.72 & 179.80 & 10.53 & 310 & 222 & 310 & 309.19 \\
\hline 105 & 1850 & 18 & 102.78 & 0.73 & 179.80 & 11.02 & 310 & 223 & 310 & 309.58 \\
\hline 106 & 1780 & 18 & 98.89 & 0.72 & 179.80 & 11.52 & 310 & 220 & 310 & 305.56 \\
\hline 107 & 1700 & 18 & 94.44 & 0.71 & 179.80 & 12.17 & 310 & 219 & 310 & 303.44 \\
\hline 108 & 1600 & 18 & 88.89 & 0.72 & 179.80 & 13.10 & 310 & 222 & 310 & 307.42 \\
\hline 109 & 1500 & 18 & 83.33 & 0.73 & 179.80 & 14.18 & 310 & 224 & 310 & 309.69 \\
\hline 110 & 1400 & 18 & 77.78 & 0.73 & 179.80 & 15.44 & 310 & 225 & 310 & 309.79 \\
\hline 111 & 1300 & 18 & 72.22 & 0.72 & 179.80 & 16.94 & 310 & 222 & 310 & 306.41 \\
\hline 112 & 1250 & 16 & 78.13 & 0.72 & 179.80 & 19.99 & 310 & 222 & 310 & 306.79 \\
\hline 113 & 1120 & 16 & 70.00 & 0.71 & 179.80 & 23.00 & 310 & 219 & 310 & 302.58 \\
\hline $114 / 115$ & 1025 & 14 & 73.21 & 0.71 & 179.80 & 29.44 & 310 & 219 & 310 & 304.79 \\
\hline 116 & 925 & 12 & 77.08 & 0.72 & 179.80 & 31.01 & 310 & 223 & 310 & 308.09 \\
\hline $117 / 122$ & 760 & 12 & 63.33 & 0.72 & 179.80 & 41.27 & 310 & 221 & 310 & 306.26 \\
\hline 118 & 670 & 10 & 67.00 & 0.74 & 179.80 & 45.75 & 310 & 228 & 310 & 307.92 \\
\hline $119 / 123$ & 590 & 8 & 73.75 & 0.73 & 179.80 & 70.23 & 310 & 225 & 310 & 301.20 \\
\hline 120 & 440 & 8 & 55.00 & 0.84 & 179.80 & 14.20 & 310 & 259 & 310 & 308.34 \\
\hline 121 & 320 & 8 & 40.00 & 0.80 & 179.80 & 19.53 & 310 & 248 & 310 & 295.84 \\
\hline 27 & 320 & 10 & 32.00 & 0.85 & 179.80 & 14.69 & 310 & 265 & 310 & 309.81 \\
\hline
\end{tabular}

Table 4. Design of Monopole with IS 800:2007

\begin{tabular}{|c|c|c|c|c|c|c|c|c|}
\hline \multirow{2}{*}{$\begin{array}{c}\text { Member } \\
\text { Numbering } \\
\text { from staad }\end{array}$} & \multicolumn{2}{|c|}{ Size } & \multirow{2}{*}{$\mathrm{D} / \mathrm{t}$} & \multirow{2}{*}{ Type Of Section } & \multirow{2}{*}{$\mathrm{N} / \mathrm{N}_{\mathrm{d}}$} & \multirow{2}{*}{ My/Mdy } & \multirow{2}{*}{$\mathrm{Mz} / \mathrm{Mdz}$} & \multirow{2}{*}{$\begin{array}{l}\text { 9.3.1 Section } \\
\text { Strength }<=1\end{array}$} \\
\hline & OD & $\mathrm{t}$ & & & & & & \\
\hline 101 & 2160 & 18 & 307.27 & Semi-Compact & 0.009 & 0.702 & 0.276 & 0.987 \\
\hline 102 & 2080 & 18 & 309.41 & Semi-Compact & 0.009 & 0.709 & 0.276 & 0.994 \\
\hline 103 & 2020 & 18 & 304.99 & Semi-Compact & 0.008 & 0.701 & 0.270 & 0.979 \\
\hline 104 & 1930 & 18 & 309.19 & Semi-Compact & 0.007 & 0.713 & 0.272 & 0.992 \\
\hline 105 & 1850 & 18 & 309.58 & Semi-Compact & 0.007 & 0.716 & 0.271 & 0.993 \\
\hline 106 & 1780 & 18 & 305.56 & Semi-Compact & 0.007 & 0.708 & 0.266 & 0.980 \\
\hline 107 & 1700 & 18 & 303.44 & Semi-Compact & 0.006 & 0.704 & 0.263 & 0.973 \\
\hline 108 & 1600 & 18 & 307.42 & Semi-Compact & 0.006 & 0.714 & 0.265 & 0.985 \\
\hline 109 & 1500 & 18 & 309.69 & Semi-Compact & 0.006 & 0.721 & 0.266 & 0.992 \\
\hline 110 & 1400 & 18 & 309.79 & Semi-Compact & 0.006 & 0.721 & 0.265 & 0.992 \\
\hline 111 & 1300 & 18 & 306.41 & Semi-Compact & 0.006 & 0.713 & 0.261 & 0.980 \\
\hline 112 & 1250 & 16 & 306.79 & Semi-Compact & 0.006 & 0.713 & 0.260 & 0.980 \\
\hline 113 & 1120 & 16 & 302.58 & Semi-Compact & 0.006 & 0.702 & 0.256 & 0.964 \\
\hline $114 / 115$ & 1025 & 14 & 304.79 & Semi-Compact & 0.007 & 0.704 & 0.254 & 0.966 \\
\hline 116 & 925 & 12 & 308.09 & Semi-Compact & 0.006 & 0.716 & 0.253 & 0.975 \\
\hline $117 / 122$ & 760 & 12 & 306.26 & Semi-Compact & 0.007 & 0.711 & 0.239 & 0.957 \\
\hline 118 & 670 & 10 & 307.92 & Semi-Compact & 0.006 & 0.732 & 0.218 & 0.956 \\
\hline $119 / 123$ & 590 & 8 & 301.20 & Semi-Compact & 0.007 & 0.722 & 0.156 & 0.885 \\
\hline 120 & 440 & 8 & 308.34 & Semi-Compact & 0.003 & 0.831 & 0.154 & 0.987 \\
\hline 121 & 320 & 8 & 295.84 & Semi-Compact & 0.002 & 0.795 & 0.145 & 0.943 \\
\hline 27 & 320 & 10 & 309.81 & Plastic & 0.000 & 0.849 & 0.140 & 0.989 \\
\hline
\end{tabular}




\section{Results and Discussion}

\subsection{Loads on Monopole}

The conductor Loads in the longitudinal direction and wind load in the transverse was calculated for a $60 \mathrm{~m}$ high and $305 \mathrm{~m}$ span on a $220 \mathrm{kV}$ electrical transmission line. The wind loads are computed for all the wind zones from the $33 \mathrm{~m} / \mathrm{s}$ to the $55 \mathrm{~m} / \mathrm{s}$. Similarly, the security loads of the monopole in the broken wire condition of the conductors is also computed for longitudinal direction. This is constant and related to the rated strength of the ACSR Conductor. The transverse wind load on the Tower and panel o forces are is depicted in the figures 2 and 3 .

\subsection{Design of Monopole}

The design of monopole members is carried out by ASCE 48-19 and compared with IS 800. The Former code adopts the Ultimate load condition, while the latter code adopts the Limit state method. The combination of Axial stress and Bending stress are considered in the American code, while the Indian code suggested the combination of the axial and strengths and bending Moment strengths with semi-compact section (buckling strength) properties. It was found that there is a $5-10 \%$ increase in the total weight of member when calculated as per IS 800. The increase in total weight was due to the material strength reduction factor of safety $\mathrm{r}_{m o}=1.1$. Hence the bending check is carried out with a factor of safety of 1.1. The design calculations In the case of ASCE 48-19 are based on $\mathrm{D} / \mathrm{t}$ ratio limits. This condition shows the bending check can be carried out directly with a stress limit as $\mathrm{F}_{\mathrm{y}}$.

\subsection{Comparison of the Longitudinal and Transverse Loads}

The transverse wind loads are computed with the basic wind speed and are increasing with wind zones. The internal parameters including Shear force, deflection and bending moment are increasing according to the change of wind speed zone.

On the other hand, the longitudinal load on the tower is computed on the conductor broken wire condition. It is constant for all the wind zones. Since it depends on the rated strength of the conductors.

Similarly, the torsional force for all the wind zones is the same. Because the parameter depends on the longitudinal Load "broken wire conductor".

The wind pressure is increased from $0.25 \mathrm{kn} / \mathrm{sqm}$ to $1.00 \mathrm{kN} / \mathrm{sqm}$ and depicted in the figure 2 . similarly the transverse wind force on the tower is increased along the height of the tower which is depicted in the figure 3.Similarly the variation of internal parameters for Shear force and Bending moment and deflection are shown in the figures 4 to 6.It is noticed that all internal parameters are increasing for the transverse directions wind forces. But the longitudinal variation is very less and it is almost constant.

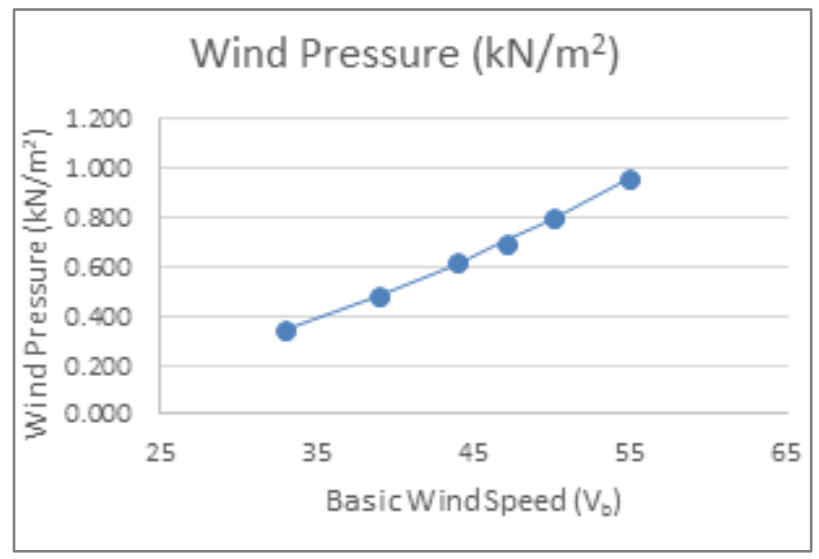

Figure 2. Variation of wind pressure

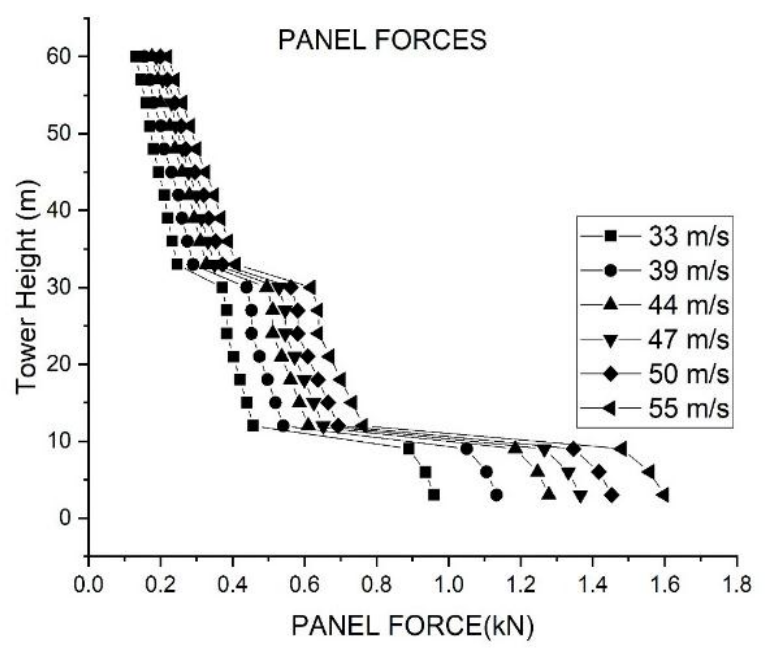

Figure 3. Transverse Wind forces on Tower

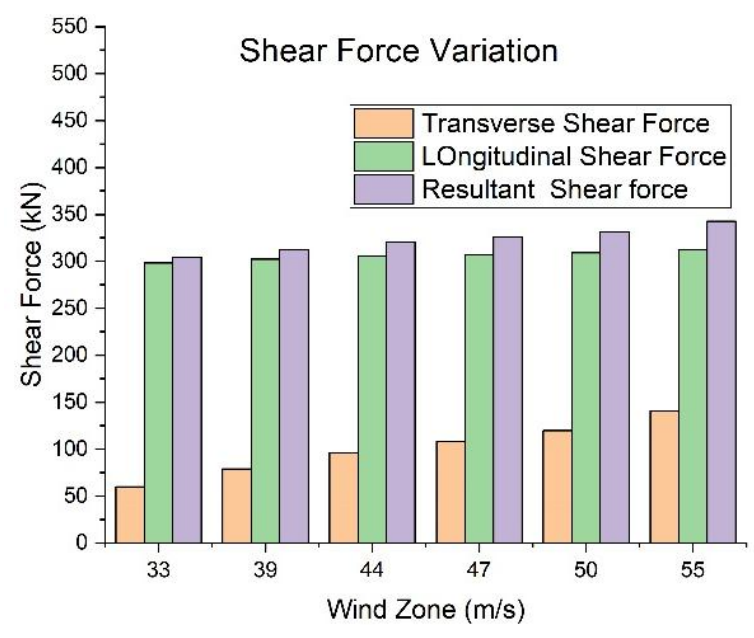

Figure 4. Variation of shear force 


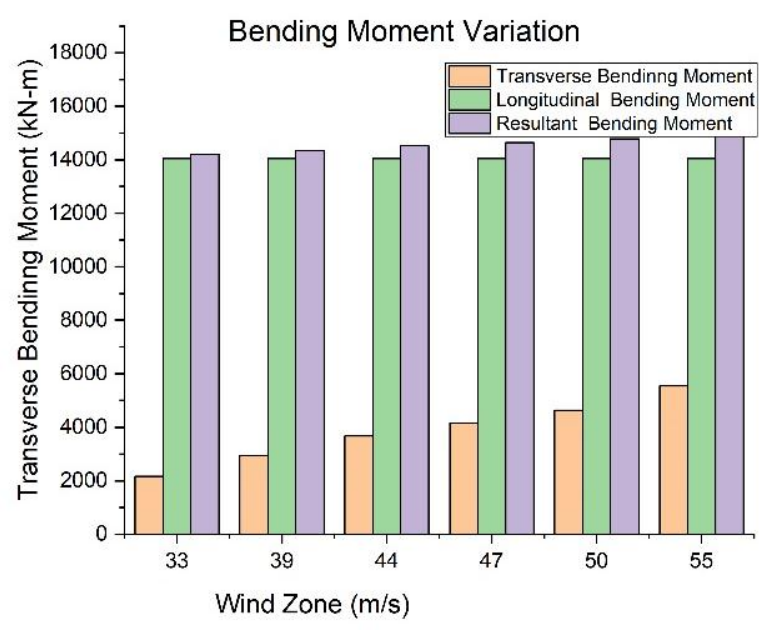

Figure 5. Variation of Bending moment

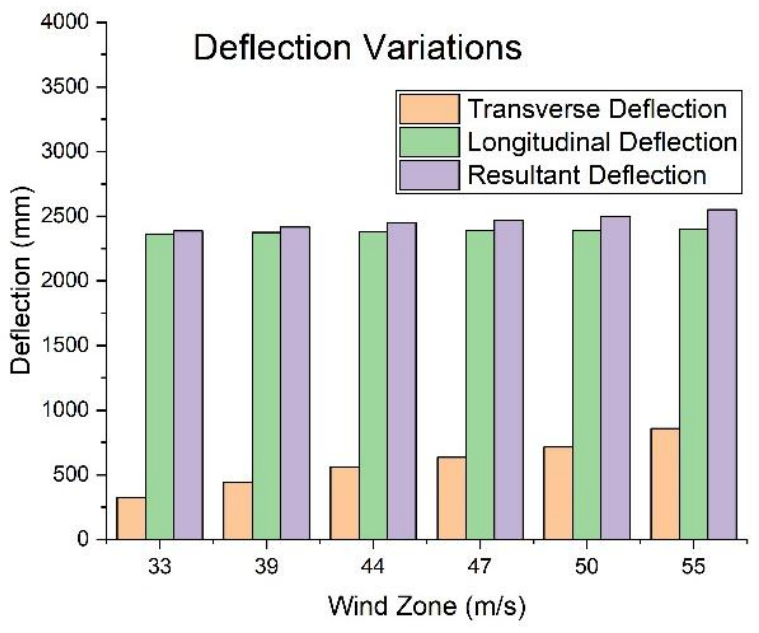

Figure 6. Variation of top deflection

\section{Conclusions}

The right of way in urban areas is more constrained. To comply with this criterion compacted vertical profile of the tower is an alternative feasible designed method. Hence monopole with composite conductors (ACSR) has been examined for the 6 wind zones from $33 \mathrm{~m} / \mathrm{s}$ to 55 $\mathrm{m} / \mathrm{s}$. The combination of the (climatic loads) Wind loads and the Longitudinal loads are adopted from the IS 802-2015 code provisions. While applying the combination of the load the Longitudinal load associated with the broken wire condition has the dominating design load on the pole structure. The combination of the loads affecting internal parameters such as transverse and longitudinal force variation, shear force bending moment and deflections and more appropriately on variation of weights for tower anatomy. After detailed discussions in the previous part, the following conclusions have been drawn. The Percentage variation of each internal parameter is deduced form the respective figures to have clear picture of the strong influence of the longitudinal forces on the resultant forces with transverse wind forces.

- It is primarily found that the wind speed is increased up to $66.60 \%$, from $33 \mathrm{~m} / \mathrm{s}$ to $55 \mathrm{~m} / \mathrm{s}$ wind zone.

- It was found from the figure2, wind pressure is increased up to $182 \%$ from the $33 \mathrm{~m} / \mathrm{s}$ to $55 \mathrm{~m} / \mathrm{s}$ wind zone.

- The maximum resultant shear force, which is depicted in the figure 4 , is increased to $12.6 \%$, from $33 \mathrm{~m} / \mathrm{s}$ to $55 \mathrm{~m} / \mathrm{s}$.

- Similarly, the resultant bending moment, which is depicted in the figure 5 , increased to $6.3 \%$, from 33 $\mathrm{m} / \mathrm{s}$ to $55 \mathrm{~m} / \mathrm{s}$.

- The resultant top deflection, which is depicted in the figure6, is increased to $1.6 \%$, from $33 \mathrm{~m} / \mathrm{s}$ to $55 \mathrm{~m} / \mathrm{s}$. Moreover, the computed deflection satisfied the 2014 CBIP monopole research report [9].

- With the above three internal parameters, the shear force has the higher variation when compared to other parameters.

- From the above points of conclusions even the wind speed is increased about 66\% from lowest wind zone to highest wind zone, the maximum internal parameter is increased to $12.6 \%$. Hence a lesser impact of the wind speed is found.

- The Longitudinal load due to broken wire condition is constant for all wind zones since it depends on the material property of the conductor only. Hence, all the internal parameters are strongly influenced by this property.

- For the financial point of view to satisfy the design criteria, the IS $800-2007$ code provides the 10\% higher weight when compared to ASCE 48-19 code provisions.

\section{Acknowledgements}

We are very grateful to experts for their appropriate and constructive suggestions to improve this template and to all the web sites.

\section{REFERENCES}

[1] C.V.J. Varma, P.K. Lal., "Transmission line manual," Publication No.268, Central Board of Irrigation and Power, New Delhi. 1997.

[2] AP TRANSCO, "Reference manuals on constructions and operational practices of EHV substations \& lines and commercial and load dispatch operations," vol. 2, 2011. https://www.aptransco.co.in/transco/images/APTRANSCO -Technical-reference-book-2011vol-i.pdf.

[3] S. Arunachalam., "Optimization of Transmission Line 
Towers," PhD thesis, Anna University, India, 1987. http://hdl.handle.net/10603/77272.

[4] N. Prasad Rao., "Failure Analysis of Transmission Towers," Ph. D thesis, Anna University, India, 2010. http://hdl.handle.net/10603/24136.

[5] K. Jayasimha., "Optimum Design of Overhead Transmission Line Tower," Ph.D. thesis, Mangalore University, India, 1996.

[6] Sriram Kalag, Prasad Yenumula., "Design of Electrical Transmission Towers, Structures and Foundations," vol I., CRC Press, Taylors and Francis Group, 2017.

[7] Indian Standard, IS 802-2015(Part-1/sec-1)," Use of Structural Steel in Overhead Transmission Line Towers", Materials and Loads, Bureau of Indian Standards, New Delhi, 2015.

[8] IEC-60286: 2017, International Standard, "Overhead transmission lines - Design criteria," ( $3^{\text {rd }}$ Edition), The International Electro technical Commission (IEC), Geneva 20, Switzerland, 2017.

[9] M L Sachdeva., V.K. Kanjlia., P P Wahi., "Manual on transmission lines - Research Report," Publication No.323, Central Board of Irrigation and Power, New Delhi, 2014.

[10] Farr, H. H., “Transmission Line Design Manual,” A Water Resources Technical Publication, United States Department of the Interior, Colorado, 1980.

[11] Indian Standard, IS 5613 (Part2/Sec1)-1985, "Code of practice for design, installation, and maintenance of overhead power lines, Part 2: Lines above $11 \mathrm{kV}$ and up to and including $220 \mathrm{kV}$, Section 1: Design," Bureau of Indian standards, New Delhi, 1985.

[12] Meng Zhang., Guifeng Zhao., Jie Li., "Nonlinear Dynamic Analysis of High-Voltage Overhead Transmission Lines," Shock and Vibration, vol. 2018, pp. 0-35, 2018. DOI: https://doi.org/ 10.1155/2018/12 47523.

[13] ASCE/SEI 48-19. American Society of Civil Engineers, "Design of Steel Transmission Pole Structures," 2020. DOI: https://ascelibrary.org/doi /book/ 10.1061/9780784411810.

[14] R. Balagopal., N. Prasad Rao., R.P. Rokade., "Simplified Model to Predict Deflection and Natural Frequency of Steel Pole Structures," Journal of the Institution of Engineers (India): Series A, vol. 99., pp. 595-607., 2018, DOI: https://doi.org/10.1007/s40030-018-0298-3.

[15] M. Ashraf, H.M. Ahmad, Z.A. Siddiqi, P. Lahore., "A Study of Power Transmission Poles," Asian Journal of Civil Engineering (Building and Housing). vol. 6, no. 6, pp. 511-532, 2005.

[16] Neftalí Rodríguez Cuevas, Roger Morales Hernández., (2009)., "Dynamic Effects Produced on Transmission Towers due to Line Cable Rupture," $11^{\text {th }}$ American Conference on Wind Engineering, San Juan Puerto Rico, June 22-26, 2009.

[17] Hatibovic, A., "Derivation of Equations for Conductor and Sag Curves of an Overhead Line Based on a Given Catenary Constant", Periodica Polytechnica Electrical Engineering and Computer Science, vol. 58, no.1, pp. 23-27, 2014. DOI: https://doi.org/10.3311/PPee.6993.
[18] H.F RAINSFORD., "Practical sag correction in catenary taping, Empire Survey Review," vol.6, no.45, pp. 402-407, 2019. DOI:10.1179/sre.1942. 6 . 45.402.

[19] Jun He, Chuanxi, Hongjun Ke, Yang Liu, Yuping Zhang, Chuangwen Dong, Hongli Li, Zhe Zhang., "A simplified calculation Method of length adjustment of datum strand for the main cable with small sag," Advances in Civil Engineering, Hindawi, (2019). DOI: http://doi.org/10.1155/2019/6075893.

[20] N.Prasad Rao, R.B.Gopal, R.P.Rokade, S.J.Mohan., "Analytical and experimental studies on $400 \mathrm{kV}$ and $132 \mathrm{kV}$ steel transmission poles," Engineering Failure Analysis, vol. 18, no 3, pp. 1018-1029, 2011, DOI:https://doi.org/10.1016/j.engfailanal.2010.12.014.

[21] M. Ashraf, H.M. Ahmad and Z.A. Siddiqi., "A study of transmission tower poles," Asian Journal of Civil Engineering, vol 6, no 6, Pp 511-532, Accessed from Research Gate, 2005.

[22] Seppa TO., "A practical approach for increasing the thermal capabilities of transmission lines," IEEE Transaction on power delivery, vol 8, no 3, pp.1536-1550, 1993. DOI: $10.1109 / 61.252680$.

[23] Luqman Hakim Mahmoud., "A study on improvement of the sag ampacity carrying level of existing $275 \mathrm{kV}$ overhead line tower by using the re-conducturing approach," ARPN journal of Engineering and Applied Sciences, vol. 10, no. 19 , pp. 8547-8551, 2015.

[24] Indian Standard, IS 875(Part3):2015, "Code of Practice for Design Loads (Other than Earthquake) for Buildings and Structures, Part-3, Wind loads", Bureau of Indian Standards, New Delhi.

[25] Indian Standard, IS 1161-2014, "Steel tubes for structural Purposes- Specification," Bureau of Indian standards, New Delhi.

[26] B. S. Kumar, K. V. G. D. Balaji, and P. C. Kumar., "The Impact of Cyclonic Importance Factor and its effect on A-type and Lean-to Roof Trusses," Disaster Advances, vol. 10 , no. 5 , pp. $42-47,2017$.

[27] B Santhosh Kumar., Balaji, K.V.G.D., Chandan Kumar Patnaikuni., "A study of $\mathrm{k} 4$ factor impact on industrial and post-cyclonic importance structures", International Journal of Civil Engineering and Technology, vol. 8., pp. 264-273, 2017.

[28] B. Santhosh Kumar, B. Ramesh, K. V. G. D. Balaji, C. K. Patnaikuni, and S. Reynold., "Along wind response of free-standing tri-pole lattice towers," International Journal of Civil Engineering and Technology, vol. 9., no. 6., pp. $172-181,2018$.

[29] C. Rathikindi, B. Santhosh Kumar Scholar, and B. Ramesh., "Prominence of K4 Factor In Gust Factor Analysis for 30m \& 60m Telecom Towers," International Journal of Civil Engineering and Technology, vol. 9, no. 8, pp. 9-17, 2018.

[30] K. V. G. D. Balaji, B. Ramesh, B. Santhosh Kumar, S. Jnanchand, and C. K. Patnaikuni., "Effect of cyclonic load factor on Monopole towers," International Journal of Engineering and Technology (UAE), vol. 7., no. 4., pp. 75-84, 2018. DOI: http://dx.doi.org/10.14419/ijet.v7i 
4.17.21807.

[31] B. Santhosh Kumar, K.V.G.D. Balaji,Chandan kumar Patnaikuni., "Perception of k 4 Factor in Cyclonic Region of India," International Journal of Engineering and Advanced Technology (IJEAT), vol. 8., no. 2s., pp. 206-208, 2018.

[32] K. V. G. D. Balaji, C. Rathikindi, B. Ramesh, and B. Santhosh Kumar., "Influence of k4 and offshore wind velocity factors on $40 \mathrm{M}$ open lattice telecommunication tower," Journal of Engineering Science and Technology, vol. 14, no. 5, pp. 2657-2669, 2019.

[33] Santhosh Kumar, Baswa., Balaji, K.V.G.D, \& Patnaikuni, Chandan kumar., (2021), "The potency of IS 875 (Part 3) 2015 code provisions on A-type trusses in the cyclonic regions of India," IOP Conference Series: Materials Science and Engineering, 1025, 012027. DOI: https://doi.org/10.1088/1757-899x /1025 /1/0 1202.

[34] Santhosh, B., Balaji, K. V. G. D., Kumar, P. C., \& Krishna,
G. V.., "Illustration of Transmission Line (Tl) Tower Design with IS 802(Part 1/Sec1)-2015 and IS 875 (Part 3):2015 Code Provisions in Wind Zone - 5 of India," ARPN Journal of Engineering and Applied Sciences, vol. 15, no. 23, pp. 2883-2891, 2020.

[35] Santhosh Kumar, B., Balaji, K. V. G. D., Patnaikuni, C. K., \& Ramesh, B., "Significance of $\mathrm{k} 1$ factor on elevated hoardings in the city limits of five wind zones of India," Civil Engineering and Architecture, vol.8., no. 6., pp.1408-1413, 2020.2 DOI: https://doi.org/10.13189/cea.2020.080623.

[36] STAAD. Pro (v8i) (Select Series 6), Structural Analysis and Design programme software, Bently Systems, Inc , USA.

[37] Bo Chen, Wei-hua Guo, Peng-yun Li, Wen-ping Xie., "Dynamic Responses and Vibration Control of the Transmission Tower-Line System: A State-of-the-Art Review", The Scientific World Journal, vol. 2014, Article ID 538457, pp. 1-20., 2014. DOI: https://doi.org/10.1155/2014/538457. 